\title{
STUDI ETNOBOTANI \& ETNOFARMAKOLOGI TUMBUHAN OBAT DI DESA CIGUNUNGSARI KECAMATAN TEGALWARU KABUPATEN KARAWANG JAWA BARAT \\ ${ }^{1}$ Neni Sri Gunarti, ${ }^{2}$ Eva Nurlina \\ ${ }^{1}$ Program Studi Farmasi, Fakultas Teknologi dan Ilmu Komputer, Universitas \\ Buana Perjuangan Karawang (neni.gunarti@ubpkarawang.ac.id) \\ ${ }^{2}$ Program Studi Farmasi, Fakultas Teknologi dan Ilmu Komputer Universitas \\ Buana Perjuangan (fm15.evanurlina@mhs.ubpkarawang.ac.id) \\ Jl. HS. Ronggo Waluyo, Telukjambe, Karawang, Jawa Barat, 41361
}

\begin{abstract}
ABSTRAK
Tumbuhan obat merupakan tumbuhan yang biasa digunakan oleh masyarakat di Indonesia sebagai bahan obat guna mengobati berbagai penyakit. Tujuan penelitian ini untuk mengetahui jenis tanaman, bagian tanaman yang digunakan, cara pemanfaatan tanaman, serta kesesuaian antara pengetahuan masyarakat desa Cigunungsari secara empiris dengan kajian etnofarmokologi yang sudah di teliti sebelumnya. Metode penelitian yang di gunakan dengan teknik metode snowball sampling yaitu pemilihan informan di dapat dari rekomendasi informan sebelumnya . Penelitian di lakukan dengan cara wawancara dan penyajian data dengan cara kuantitatif yang dilakukan dengan mengukur persentase sitasi. Hasil menunjukan terdapat 23 jenis tanaman obat yang digunakan sebagai obat oleh masyarakat di desa Cigunungsari Kecamatan Tegalwaru Kabupaten karawang. Bagian tanaman yang sering digunakan yaitu daun sebanyak $69,7 \%$, cara penggunaan yang sering dilakukan yaitu dengan cara diminum sebanyak $73,91 \%$, dan cara pengolahan yang paling sering dilakukan adalah dengan cara di rebus yaitu sebanyak $56,52 \%$, serta tidak semua tanaman memiliki kesesuaian dengan kajian etnofarmakologi mengenai khasiat dari tanaman tersebut.
\end{abstract}

Kata kunci : Etnobotani, etnofarmakologi, tumbuhan obat, snowball sampling.

\begin{abstract}
Medicinal plants are plants commonly used by people in Indonesia as medicinal ingredients to treat various diseases. The purpose of this study was to determine the types of plants, parts of plants used, how to use the plants, and the suitability between the knowledge of the Cigunungsari village people empirically with ethnopharmocological studies that have been studied previously. The research was conducted by interviewing and presenting data in a quantitative way by measuring the percentage of citations. The results showed that there were 23 types of medicinal plants used as medicine by the community in the village of Cigunungsari. Parts of plants that are often used are leaves as much as $69.7 \%$, the method of use that is often done is by drinking as much as $73.91 \%$, and the method of processing most often done is by boiling as much as $56.52 \%$.
\end{abstract}

Keywords: Ethnobotany, ethnopharmacology, medicinal plants, snowball sampling. 


\section{PENDAHULUAN}

Banyak penelitian tentang Studi etnobotani yang di lakukan diberbagai daerah untuk mengetahui jenis tumbuhan yang sering digunakan sebagai pengobatan. Menurut Safryadi et al,2017 "telah berhasil menemukan 41 tanaman yang berkhasiat sebagai obat, serta bagian tanaman yang digunakan sebagai pengobatan, dan pemanfaatan obat oleh masyarakat Desa Rema Kecamatan Bukit Tusam Kabupaten Aceh Tenggara".

Selain itu, sebelum nya telah dilakukan penelitian oleh Gunarti, 2018 "studi etnobotani di Desa Mekarbuana Kecamatan Tegalwaru Kabupaten Karawang dan berhasil menemukan 25 tanaman yang berkhasiat sebagai obat, serta bagian tanaman yang digunakan sebagai pengobatan, dan pemanfaatan obat oleh masyarakat Desa Mekarbuana Kecamatan Tegalwaru Kabupaten Karawang, namun tidak mengidentifikasi menegenai kesesuaian antara pengetahuan masyarak tentang penggunaan tumbuhan obat dengan kajian etnofarmakologi yang sudah dilakukan penelitian nya".

Berdasarkan uraian di atas maka dilakukan penelitian yang berjudul "Studi Etnobotani \& Etnofarmakologi Tumbuhan Obat di desa Cigunungsari Kecamatan Tegalwaru Kabupaten Karawang Jawa barat". Penelitian ini bertujuan untuk mengetahui jenis tanaman obat, bagian tanaman yang digunakan serta cara pemanfaatannya dalam penyembuhan suatu penyakit dan kesesuaian antara pengetahuan masyarakat secara empiris dengan kajian etnofarmakologi yang sudah ada sebelumnya.

\section{METODE PENELITIAN}

Jenis penelitian ini yaitu penelitian cross sectional yaitu menggunakan kombinasi metode kualitatif dan kuantitatif. Penelitian kualitatif dilakukan dengan cara wawancara pada beberapa informan. Sedangkan untuk penyajian data kuantitatif dapat dilakukan dengan mengukur persentase sitasi. 


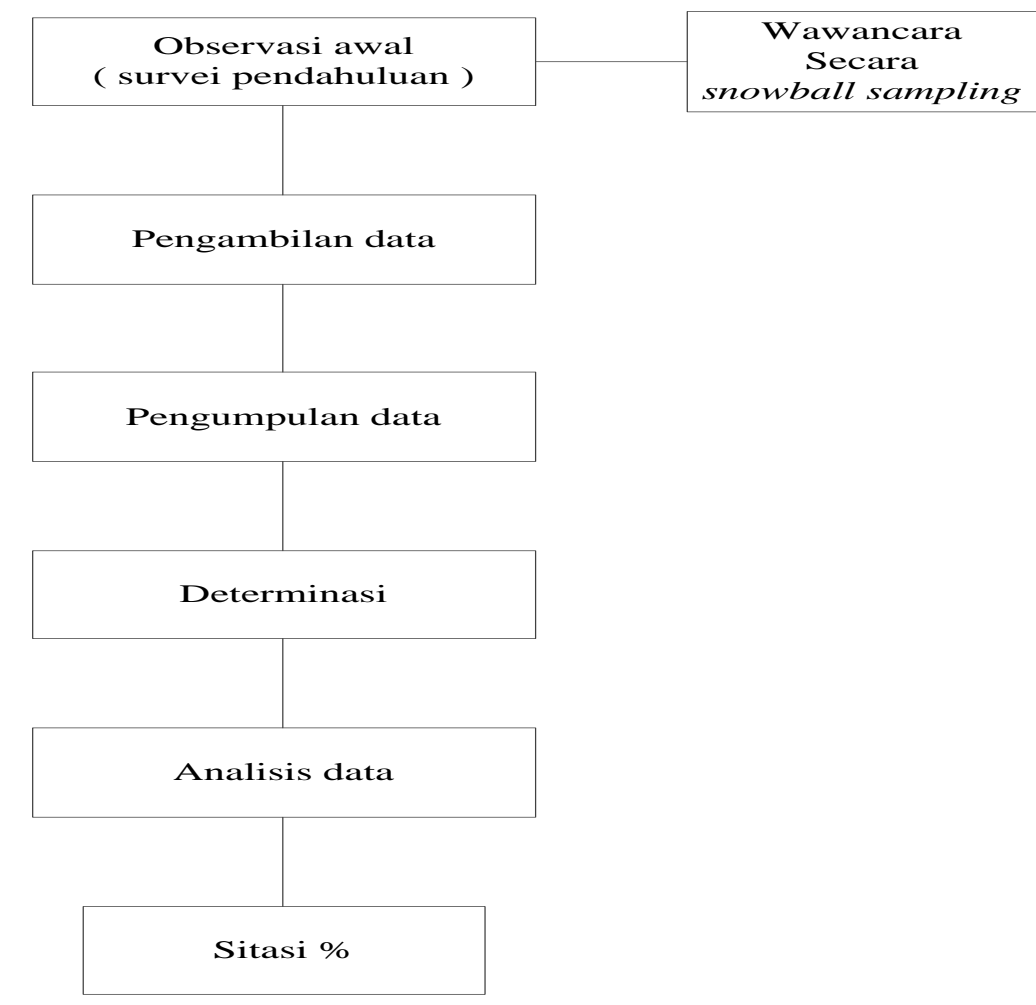

\section{Analisis data}

Teknik analisis data yang digunakan deskriptif kuantitatif menggunakan metode Sitasi (\%). 


\section{HASIL DAN PEMBAHASAN}

\begin{tabular}{|c|c|c|c|c|}
\hline Nama tanaman & $\begin{array}{c}\text { Bagian tanaman yang } \\
\text { digunakan }\end{array}$ & Cara penggunaan & Cara pengolahaan & Khasiat Secara Empiris \\
\hline Kumis kucing & Daun & Diminum & Direbus & Hipertensi \\
\hline Kemangi & Daun & Diminum & Direbus & Kolesterol \\
\hline Mahkota dewa & Buah & Diminum & Direbus & Diabetes \\
\hline sirih hijau & Daun & Diminum & Direbus & Keputihan \\
\hline sambang darah & Daun & Ditempel & Ditumbuk & Obat luka \\
\hline cecendet/ciplukan & Batang, daun,akar & Diminum & Direbus & Kolesterol \\
\hline Kersen & Daun & Diminum & Direbus & Diabetes \\
\hline Singkong madinah & Daun & Dioles & Diremat & Demam \\
\hline Binahong & Daun & Diminum & Direbus & Hipertensi \\
\hline Alpukat & Daun & Diminum & Direbus & Hipertensi \\
\hline Sirsak & Daun & Diminum & Direbus & Kolesterol \\
\hline Suji & Daun & Diminum & Direbus & Panas dalam \\
\hline Salam & Daun & Diminum & Direbus & Hipertensi dan kolesterol \\
\hline Daun iler & Daun & Ditempel & Ditumbuk & Obat luka \\
\hline Kunyit kuning & Rimpang & Diminum & Diparut & Nyeri haid \\
\hline Betadine & Buah & Dioleskan & Ditumbuk & Obat luka \\
\hline Pepaya & Daun & Diminum & Direbus & Diabetes \\
\hline Mengkudu & Buah & Diminum & Dihaluskan & Hipertensi \\
\hline Jambu biji & Daun & Diminum & Direbus/dimakan & Diare \\
\hline Serai wangi & Batang & Diikat & Ditumbuk & Patah tulang \\
\hline Daun saga & Daun & Diminum & Diremat & Panas dalam \\
\hline Jahe & Rimpang & Diminum & Direbus & Pegal-pegal \\
\hline Lidah buaya & Daging & Dioleskan & Diremat & Obat luka \\
\hline
\end{tabular}


Tabel 1 Cara Penggunaan Tumbuhan

perhitungan sitasi \% cara penggunaan tumbuhan

\begin{tabular}{clccc} 
No & Cara Penggunaan Tumbuhan & Frekuensi Sitasi (NP) & N & Sitasi \% (N=23) \\
\hline 1 & Diminum & 17 & 23 & 73,91 \\
2 & Dioleskan & 3 & 23 & 13,04 \\
3 & Ditempel & 2 & 23 & 8,70 \\
4 & Diikat & 1 & 23 & 4,35 \\
4 & Dimakan & 1 & 23 & 4,35 \\
\hline
\end{tabular}

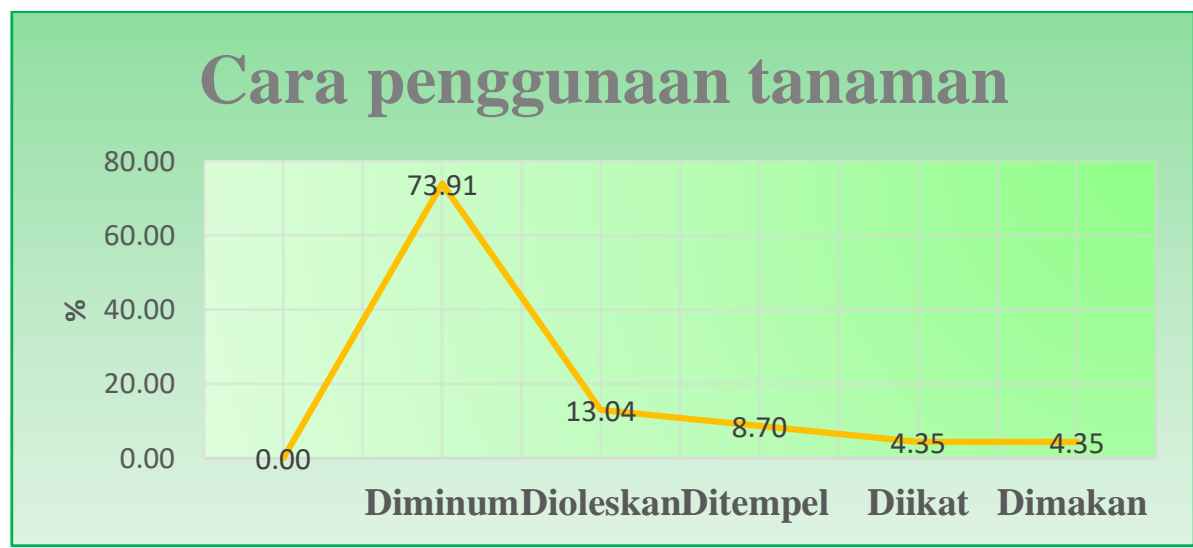

Gambar 1. Cara penggunaan tanaman

Table 2. Perhitungan sitasi \% cara pengolahan tanaman

\begin{tabular}{llccc} 
No & Cara Pengolahan Tumbuhan & Frekuensi Sitasi (NP) & N & $\begin{array}{c}\text { Sitasi \% } \\
\text { (N=23) }\end{array}$ \\
\hline 1 & Direbus & 13 & 23 & 56,52 \\
2 & Diremat & 3 & 23 & 13,04 \\
3 & Ditumbuk & 4 & 23 & 17,39 \\
4 & Diparut & 1 & 23 & 4,35 \\
5 & Dihaluskan & 1 & 23 & 4,35 \\
6 & Dipetik & 1 & 23 & 4,35 \\
\hline
\end{tabular}




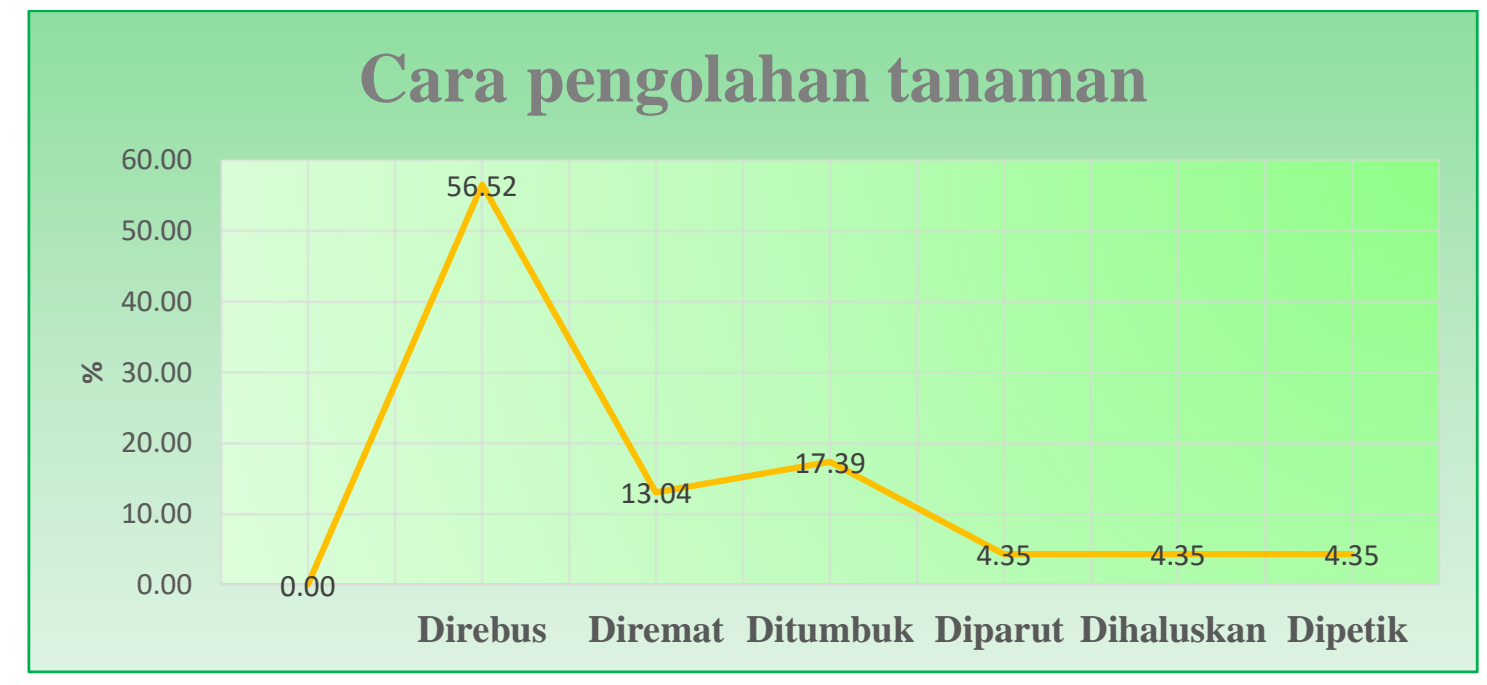

Gambar 2. Cara Pengolahan Tanaman

Tabel 3. Perhitungan sitasi \% Bagian tanaman yang digunakan

\begin{tabular}{llccc}
\hline No & $\begin{array}{c}\text { Bagian tanaman yang } \\
\text { digunakan }\end{array}$ & $\begin{array}{c}\text { Frekuensi Sitasi } \\
(\mathbf{N P})\end{array}$ & $\mathbf{N}$ & $\begin{array}{c}\text { Sitasi \% } \\
(\mathbf{N = 2 3})\end{array}$ \\
\hline 1 & Daun & 16 & 23 & 69,57 \\
2 & Batang & 2 & 23 & 8,70 \\
3 & Akar & 1 & 23 & 4,35 \\
4 & Buah & 3 & 23 & 13,04 \\
5 & Rimpang & 2 & 23 & 8,70 \\
6 & Daging & 1 & 23 & 4,35 \\
\hline
\end{tabular}

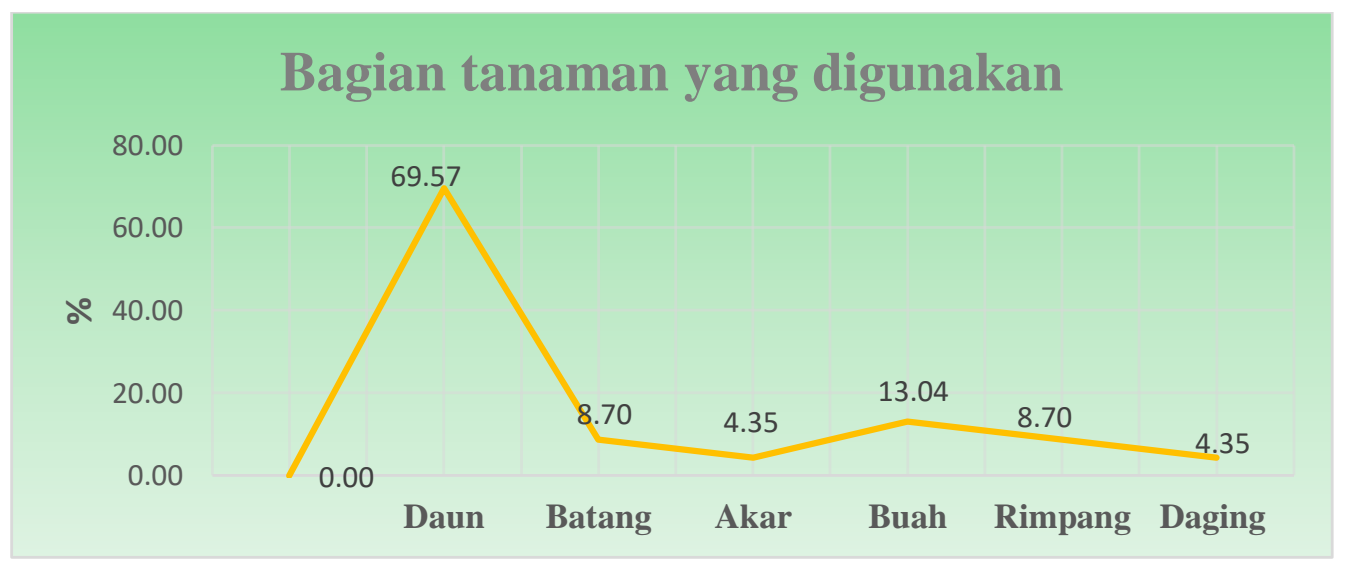

Gambar 3.Bagian Tanaman yang Digunakan 


\section{KESIMPULAN}

1. Terdapat 23 jenis tanaman yang digunakan oleh masyarakat untuk pengobatan diantaranya : singkong madinah, daun kersen, ciplukan, mengkudu, mahkota dewa, sirih, sambang darah, suji, salam, alpukat, binahong, kumis kucing, jahe, kunyit kuning, sirih wangi, daun sirih, lidah buaya, jawer kotok, daun saga, kemangi, jambu biji, papaya, mengkudu.

2. Bagian tanaman yang digunakan yaitu daun, batang, buah, akar, daging, rimpang dan yang sering digunakan yaitu daun sebanyak 69,7\%.

3. Cara penggunaan yag sering dilakukan yaitu dengan cara diminum, dimakan, ditempel, dioleskan, diikat dan yang paling sering yaitu dengan cara diminum yaitu sebanyak $73,91 \%$, dan cara pengolahan yang paling sering adalah dengan cara di rebus yaitu sebanyak $56,52 \%$.

4. Hasil dari studi literatur menunjukan Tidak semua sesuai antara pengetahuan secara empiris masyarakat mengenai tanaman yang digunakan sebagai obat dengan kajian etnofarmakologi beberapa hasil penelitian sebelumnya.

\section{DAFTAR PUSTAKA}

Apryanto, 2015. Studi Etnobotani Tumbuhan Obat Suku Seko di Desa Tanah Harapan Kabupaten Sigi Sulawesi Tengah. Jurnal Biocelebes. Vol. 9. No. 2.

Gunarti N.S. 2018. Laporan Kajian Etnomedisin Desa Mekarbuana Kecamatan Tegalwaru Kabupaten Karawang.

Hidayah. W, Dewi. K \& Enny. F. 2016. Isolasi, Identifikasi Senyawa Steroid dari Daun Getih-Getihan (Rivina humilis L.) dan Uji Aktivitas sebagai Antibakteri. Journal of Scientific and Applied Chemistry.

Ilkafah,2018. Daun Kersen (Muntingia Calabura L.) Sebagai Alternatif Terapi Pada Penderita Gout Artritis. Pharmacy Medical Journal. Vol.1 No.1.

Kurnia. D, Prima. H. R. 2019. Aktivitas Farmakologi Dan Perkembangan Produk Dari Lidah Buaya (Aloe vera L.). Jurnal Pharmascience, Vol. 06 , No.01.

Kurniati. I. 2012. Hubungan hiperkolesterolemia dengan kadar SGOT dan SGPT. Jurnal kedokteran dan kesehatan Universitas Lampung, Vol.2, No . 
Mandasari V. 2018. Studi Etnofarmasi Penggunaan Tumbuhan Obat Sebagai Antidiare Oleh Masyarakat Suku Tengger Kecamatan Tosari Kabupaten Pasuruan. Skripsi.Jember.Universitas Jember.

Mufida, Nurdin. R \& Supriadi. 2018. Efek Ekstrak Daun Alpukat (Persea Americana Mill.) Dalam Menurunkan Kadar Kolesterol Darah Pada Mencit (Mus Musculus). Jurnal Akademika Kimia. Volume, 7, No. 1.

Nisyapuri,Johan\&Ruhyat.2018. Studi etnobotani tumbuhan obat di Desa Wonoharjo, Kabupaten Pangandaran, Jawa Barat. Pros sem nas masy biodiv indon. 2: 122-132 ISSN: 2407-8050.

Ningsih,2016. Studi Etnofarmasi Penggunaan Tumbuhan Obat Oleh Suku Tengger Di Kabupaten Lumajang Dan Malang, Jawa Timur. Pharmacy. 3. 01 :1693-3591. Nurdiani,2014. Teknik Sampling Snowball Dalam Penelitian Lapangan. ComTech.5: 1110-1118.

Pertiwi R D, Joni K, Graha A P. Uji Aktivitas Antibakteri Formulasi Gel Untuk Sariawan Dari Ekstrak Daun Saga ( Abrus Precatorius Linn. ) Terhadap Bakteri Staphylococcus Aureus. Jurnal Ilmiah Manuntung. Vol 2. No 2.

Priatna. M, Dian. C. 2015. Efek Antidiare Ekstrak Etanol Daun Sambang Getih Pada Mencit Secara Transit Intestinal. ISBN : 978-602-73060-1-1

Priyoto, Tri widyastuti, Pengobatan Herbal Untuk Penyakit Ringan. (Yogyakarta: Graha Ilmu, 2014), h.56.

Pundyawanti, Mariska. D.A. 2018. Patient Center Care Dalam Penanganan Diabetes Melitus Obese Geriatri Secara Koprehensif Papaya Leaf Extract ( Carica Papaya L) As Dm Type 2 Ektrak Daun Pepaya Sebagai Anti Dm Tipe 2. Annual Pharmachy Conference. 5:1.

Sapriyadi,Aisyah,Mahdalena. Kajian Etnobotani Melalui Pemanfaatan Tanaman Obat Di Desa Rema Kecamatan Bukit Tusam Kabupaten Aceh Tenggara. Prosiding Seminar Nasional Biotik: 978-602-60401-3-8. 